\title{
Structural Analyses of Total Anionic Cyclosophoraoses Synthesized by Rhizobium meliloti 2011
}

\author{
Dong-huyk Seo, Sanghoo Lee, Hey-lin Park, Dong-Heui Yi, Eunjung Ji, Dae-Ho Shin, ${ }^{\dagger}$ and Seunho Jung ${ }^{\star}$ \\ Department of Microbial Engineering and Bio/Molecular Informatics Center, Konkuk University, \\ Hwayang-dong 1, Gwangin-git, Seaul 143-701, Korea \\ ${ }^{\dagger}$ Korea Basic Science Insitute (KBSI), Seoul Branch, Seoul 136-739, Korea \\ Received Febriary: 20, 2002
}

Keywords : ESI-MS, Rhizobinm meliloti 2011. Cyclic oligosaccharides, Anionic cyclosophoraoses.

Cyclosophoraoses (Figure 1) are unique molecules found almost exclusively in the members of Rhizobiaceae family, which are fast growing soil bacteria. These are a class of unbranched cyclic oligosaccharides composed of $\beta-(1 \rightarrow 2)$ D-glucans varying in size from 17 to 40 as a neutral or anionic form. Recently, many studies have been focused on the inclusion complexation of cyclosophoraoses as the effective solubilizer of various insoluble compounds such as ergosterol, fluoroscein, indomethacin, paclitaxel and vitamins. ${ }^{7 \cdot 6}$ The anionic cyclosophoraoses located in the periplasmic place of the bacteria played important roles on the osmotic regulation as well as on the successful root-nodule formation of Rhizobium species at the initial stage of the nitrogen fixation. ${ }^{7.9}$ The partial structures of anionic cyclosophoraoses were known to be substituted with charged molecules such as sn-glycerol-1-phosphate, succinic acid, and methylmalonic acids, ${ }^{10-14}$ depending on the kind of Rhizobitw species. The structures of anionic cyclosophoraoses were deduced from a fast atom bombardment mass spectrometry (FAB-MS) ${ }^{13}$ and NMR spectroscopy. ${ }^{10,11,15-17}$ However, these methods did not show the complete structures of exact anionic cyclosophoraoses. Their analyses were restricted to a few isolated fractions of anionic cyclosophoraoses. Moreover, any investigations were not performed on whether all the neutral cyclosophoraoses were to be substituted with anionic moieties or not. So, it still remains unclear whether all the neutral cyclosophoraoses could be substrates for anionic ones.

In this study, we first present the structural analyses of the whole anionic cyclosophoraoses synthesized from Rhizobium meliloti 2011 by an electrospray ionization - mass spectrometric (ESI-MS) and two-dimensional NMR spectroscopic methods. Especially, ESI-MS has been widely used in various fields as a high-efficiency and high-resolution separation technique. ${ }^{18}$ Recently, highly sulfated cyclic oligosaccharides have been successfully characterized by this technique. ${ }^{19}$ Using this ESI-MS techniques, we identified the degree of anionic substitution (DAS) for the anionic cyclosophoraoses produced by $R$. meliloti 2011 in relation with the size distribution. Additional two-dimensional NMR spectroscopic analysis was also used to confurm the exact position of the

"Corresponding author. Phone: +82-2-450-3520; Fax: +82-2-452361 l: E-mail: shjung@konkuk.ac.kr

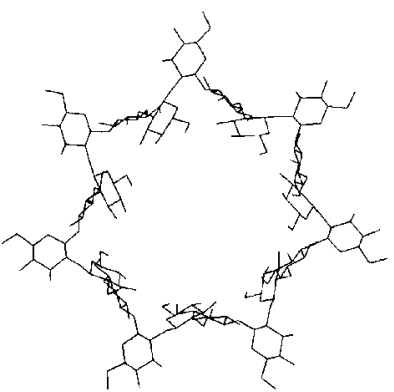

A

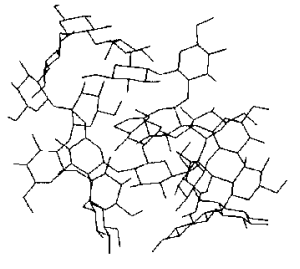

B
Figure 1. Proposed molecular models of neutral cyclosophoraoses. (A) Palleschi $a t a l^{\prime}{ }^{\prime}$ (B) Jung et $a l^{2}$

substituted glycerolphosphates for the isolated anionic cyclosophoraoses from $R$. meliloti 2011 .

\section{Experimental Section}

Bacterial strain and culture condition. The bacterial strain used in this study was Rhizobitm meliloti 2011 . It was generously provided by Dr. R. I. Hollingsworth, MSU, E. Lansing, Michigan, U.S.A. For large-scale isolation of cellular glucans, $25 \mathrm{~mL}$ preculture was inoculated into $500 \mathrm{~mL}$. GMS standard medium ${ }^{2 j}$ and cells were cultured to late logarithmic phase and incubated at $30^{\circ} \mathrm{C}$, at $150 \mathrm{rpm}$ on a rotary shaker.

Preparation of cyclosophoraoses. Cells were harvested by centrifugation $\left(8,000 \mathrm{rpm}\right.$, at $\left.4{ }^{\circ} \mathrm{C}\right)$, washed once with a saline solution, and subjected to the hot-ethanol extraction method. Cells were then extracted with $40 \mathrm{~mL}$ of $75 \%$ (v/v) ethanol at $70^{\circ} \mathrm{C}$ for $30 \mathrm{~min}$. After centrifugation, the supernatant was concentrated on a vacuum rotary evaporator. The concentrated sample was chromatographed on a Sephadex G-50 column $(1.5 \times 110 \mathrm{~cm})$ at a rate of $20 \mathrm{~mL} / \mathrm{h}$ and the eluant fractions ( $7 \mathrm{~mL}$ ) were assayed for carbohydrate by a phenol-sulfuric acid method. The fractions containing cyclosophoraoses were pooled, concentrated, and desalted by a Sephadex G-15 column $(2 \times 27 \mathrm{~cm})$ under the conditions described above.

Preparation of anionic cyclosophoraoses. The desalted sample was then applied to a column $(2 \times 35 \mathrm{~cm})$ of DEAEcellulose to separate neutral and anionic cyclosophoraoses. 
The column was first washed with distilled water containing $1 \mathrm{mM} \mathrm{KCl}$, and a concentration gradient was applied from 1 $\mathrm{mM}$ to $100 \mathrm{mM} \mathrm{KCl}$.

Electrospray ionization mass spectrometry. ESI-MS of the anionic cyclosophoraoses was carried out on a Micromass Quattroll (Altrincham, UK) double quadrupole mass spectrometer equipped with an ion spray source and connected to a syringe pump for sample injection. Electrospray spectra were recorded in the negative mode with the ionspray voltage set at $3.50 \mathrm{kV}$ and the cone voltage at $30 \mathrm{~V}$. Scanning was performed in the multi-channel analyzer mode from $\mathrm{m} / \mathrm{z} 500$ to $\mathrm{m} / \mathrm{z} 4000$. The samples were dissolved in water/acetonitrile $(1: 1, \mathrm{v} / \mathrm{v})$ at a final concentration of about $0.5 \mathrm{mg} / \mathrm{mL}$. The sample solution was introduced into the ESI source at a constant flow rate of $5 \mu \mathrm{L} / \mathrm{min}, 80^{\circ} \mathrm{C}$.

IMR spectroscopy of anionic cyclosophoraoses. NMR spectroscopic analyses were performed on a Bruker AMX spectrometer $\left(500 \mathrm{MHz}\right.$ for ${ }^{1} \mathrm{H}, 125 \mathrm{MHz}$ for ${ }^{13} \mathrm{C}$ ) at $25^{\circ} \mathrm{C}$. The purified anionic cyclosophoraoses were dissolved in deuterated water $\left(\mathrm{D}_{2} \mathrm{O}, 99.96 \%\right)$. ${ }^{3 l} \mathrm{P}$ NMR spectra were recorded with a Bruker DRX-500 NMR spectrometer operating at $a^{31} \mathrm{P}$ frequency of $202 \mathrm{MHz}$. A sample of $20 \mathrm{mg}$ was dissolved in $\mathrm{D}_{2} \mathrm{O}$ with an external standard solution of inorganic phosphoric acid. Measurements were performed in a $5 \mathrm{~mm}$ probe using $5 \mathrm{~mm}$ sample tubes at $25^{\circ} \mathrm{C}$.

\section{Results and Discussion}

XMR spectroscopic analysis. The presence of glycerol-

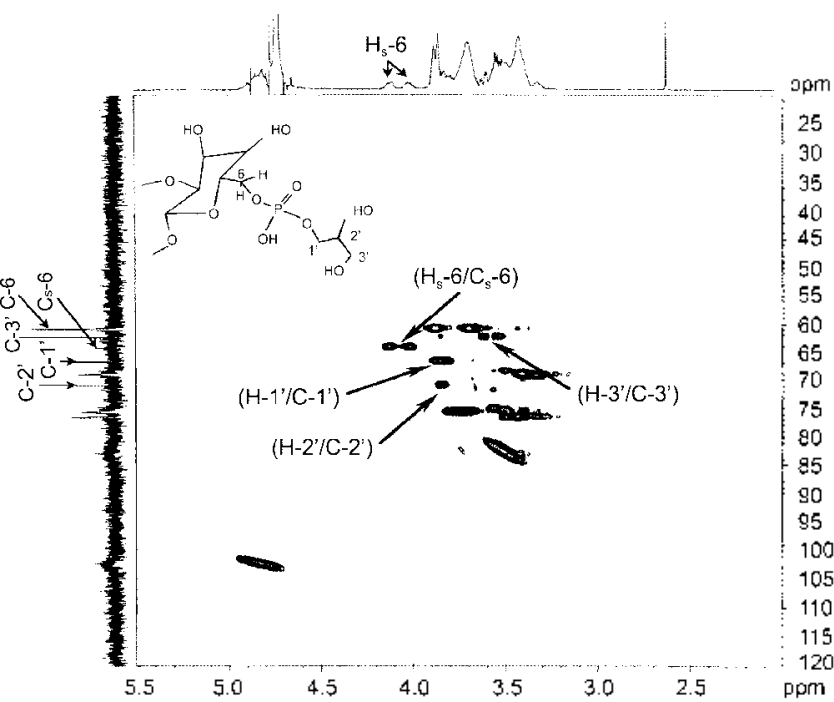

Figure 2. HSQC spectrum of anionic cyclosophoraoses. Snglycerol-1-phosphate residues were directly linked to the C-6 of glucose residue through a phosphodiester linkage. $\left(\mathrm{C}_{5}-6\right.$ and $\mathrm{H}_{s}-6$ : $\mathrm{C}-6$ and $\mathrm{H}-6$ of the glucose residue substituted with glycerol-1. phosphate).

1-phosphates in the anionic cyclosophoraoses was confirmed by NMR spectroscopic analysis. Each of the peaks at $66.8,71.1,62.5$ ppm was assigned to $\mathrm{C}-1^{1}, \mathrm{C}-2^{1}$, and $\mathrm{C}-3^{1}$ of sn-glycerol-1-phosphate residues, respectively. Each resonance of $\mathrm{C}-1$ to $\mathrm{C}-6$ of anionic cyclosophoraoses was also assigned at $102.4,83.1,75.8,69.1,76.7$, and $61.0 \mathrm{ppm}$.

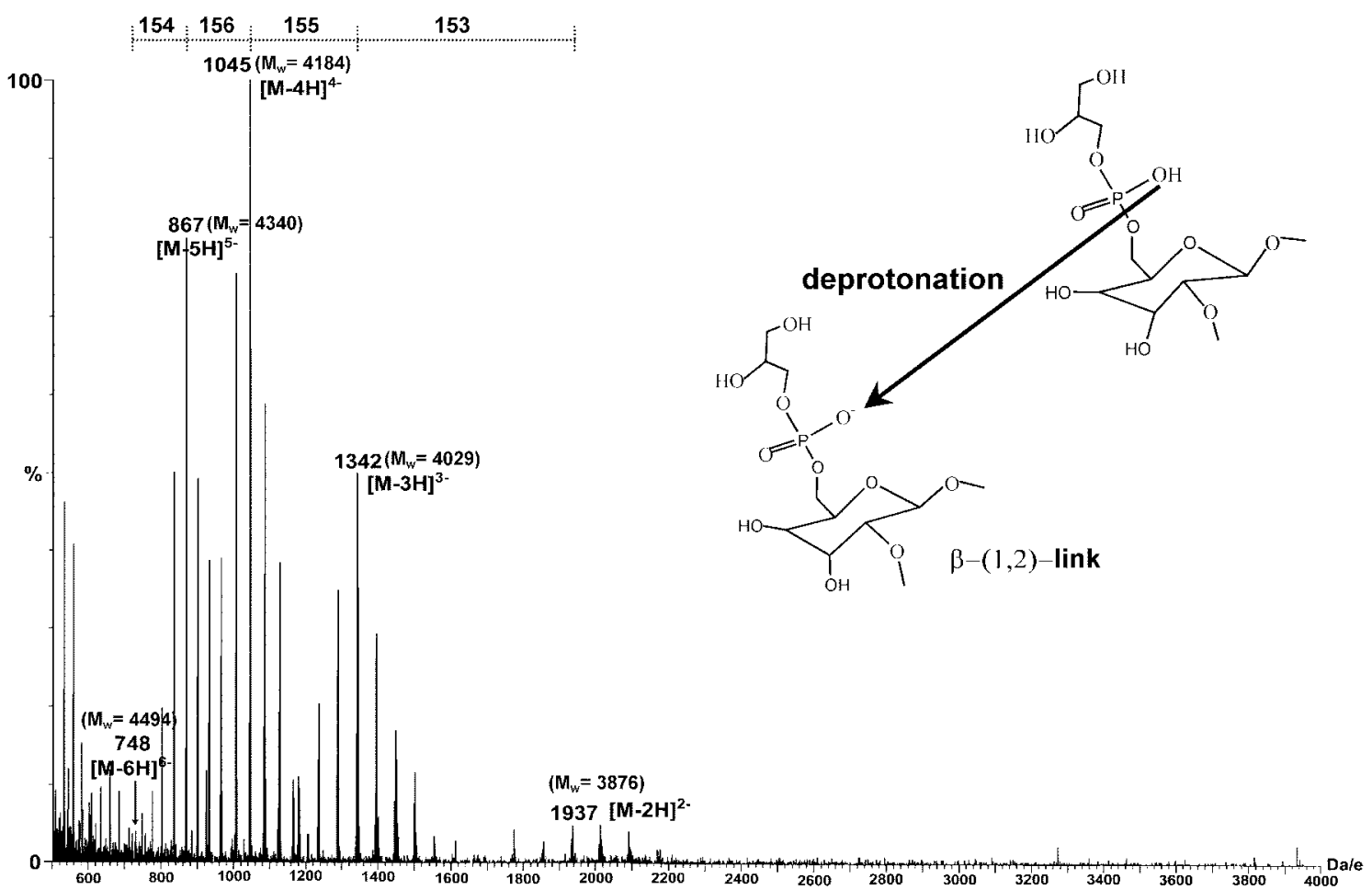

Figure 3. ESI mass spectrum of anionic cyclosophoraoses. The mass units at $748,867,1045,1342$ and 1937 correspond to the anionic cyclosophoraoses substituted with 2 to 6 glycerol-1-phosphate moieties in DP 22, respectively. Calculated molecular weights $\left(M_{w}\right)$ were shown in parenthesis. Mass difference of 155 comesponds to the molecular weight of glycerol-l-phosphate. (Inuer diagram: The deprotonation scheme of anionic cyclosophoraoses.) 
Table 1. Expected and observed mass units of total anionic cyclosophoraoses isolated from $R$. meliloti 2011 (Expected: The calculated values, Observed: The values acquired from ESI mass spectrum)

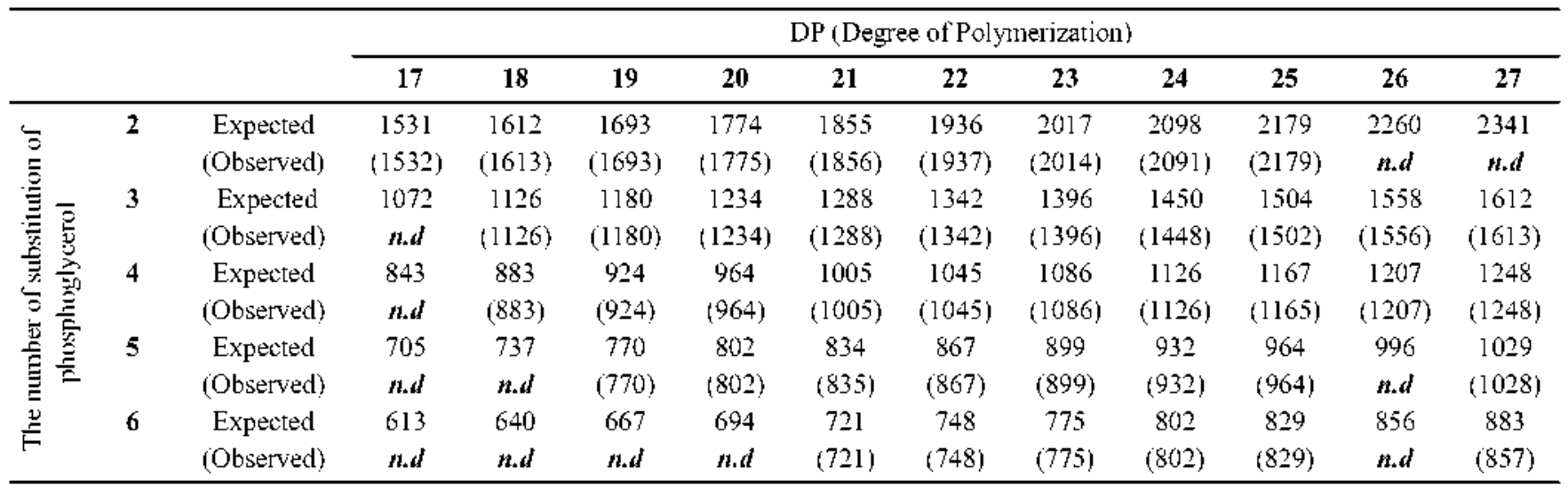

n.t: not detected.

respectively (data not shown). Phosphate substitution that occurs at C-6 of the glucose residues resulted in shift of the glucose $\mathrm{C}-4, \mathrm{C}-5$, and $\mathrm{C}-6$ resonance. Particularly, the C-6 peak in substituted glucose residues shifted to $64.4 \mathrm{ppm}$ because of the anionic substitution. The chemical shifts of C-4, C-5 resonances also moved a little to an upfield area. Figure 2 shows the heteronuclear single quantum coherence (HSQC) spectrum of isolated anionic cyclosophoraoses. Methylene groups bound to the C-6 of glucose residues substituted with sn-glycerol-1-phosphate and the three carbons of glycerol were assigned in Figure 2. It showed the C- 6 of substituted glucose residues was directly bound to the phosphate of anionic cyclosophoraoses. Upfield Chemical shift of the C-1' of glycerol also indicated that the phosphate was linked to that position. On the while, the presence of phosphate groups of anionic cyclosophoraoses was confurmed by ${ }^{31}$ P-NMR spectroscopy (data not shown). Thus, in the case of anionic cyclosophoraoses synthesized from $R$. meliloti 2011, only $s n$-glycerol-1-phosphate residues were directly linked to some glucose residues through phosphodiester linkages at the C-6 position.

ESI-Mass spectrometry. Figure 3 shows the total mass spectrum of the anionic cyclosophoraoses of $R$. meliloti 2011. Spectrum was acquired in the negative-ion mode by deprotonation, $[\mathrm{M}-\mathrm{H}]^{-}$. The pattern of this spectrum looked similar to that of isolated fraction from DEAE-cellulose chromatography ${ }^{7,2]}$ The ESI-MS spectrum of anionic cyclosophoraoses contained $-2\left([\mathrm{M}-2 \mathrm{H}]^{3-}\right)$ to -6 charged $([\mathrm{M}-$ $6 \mathrm{H}]^{6-}$ ) molecules with complex peak sets formed. The mass units at $748,867,1045,1342$ and 1937 correspond to the

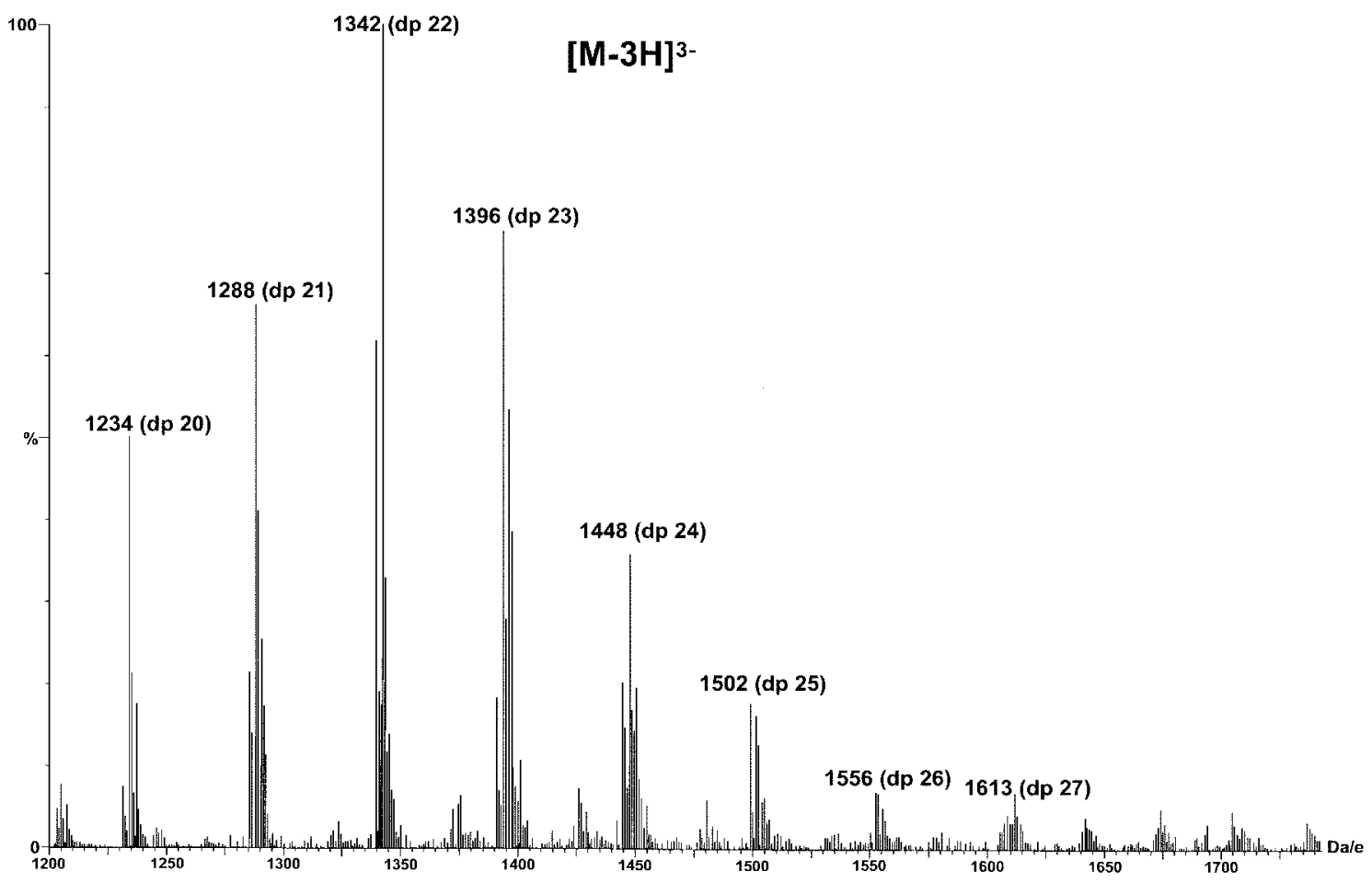

Figure 4. ESI mass spectrum of $[\mathrm{M}-3 \mathrm{H}]^{3-}$ of anionic cyclosophoraoses. 
anionic cyclosophoraoses of the degree of polymerization (DP) 22, respectively. The molecular weight $\left(\mathrm{M}_{\mathrm{w}}\right)$ difference between the major peaks is about 155 corresponding to one phosphoglycerol moiety as a substituent. On the while, most major peaks of anionic cyclosophoraoses appeared around DP 22, which were also major in neutral ones in $R$. meliloti $2011^{22}$

Each of expected or observed masses of the anionic cyclosophoraoses of Figure 3 was sorted out in Table 1. All the masses of observed peaks were excellently explained by the prediction based on the charged glycerol-1-phosphate substituents. The degree of substitution of anionic moieties was turned out to be dependent on the DP (degree of polymerization) of cyclosophoraoses (Table 1). The larger DP of cyclosophoraoses, the more degree of substitutions of glycerol1 -phosphate moieties was evidently observed. In the anionic cyclosophoraoses larger than DP 21, two to six glycerol-1phosphate moieties were attached to the cyclosophoraoses. However, in the case of DP 17, only two glycerol-1phosphate moieties were bound to the cyclosophoraoses. This observation clearly indicates that not all the neutral cyclosophoraoses are substrates for anionic ones. Depending on their sizes, the degree of anionic substitution was changed. It might give an answer why some of cyclosophoraoses are so large in degree of polymerization like DP 40 . The larger cyclosophoraoses can possess the more charged moieties within the neutral ones so that microorganism can be more effectively adapted to external osmotic regulation. Figure 4 shows the ESI mass spectrum of $[\mathrm{M}-3 \mathrm{H}]^{3-}$ anionic cyclosophoraoses substituted with three glycerol-1-phosphate molecules, which clearly indicated that each of the mass differences between adjacent major peaks was 162 corresponding to one glucose unit.

In the present study, we showed that anionic cyclosophoraoses contained the C-6 of substituted glucose residues, directly bound to the phosphate of $s n$-glycerol-1-phosphate and used first ESI-MS to find out the dependence of DAS (degree of anionic substitution) of cyclosophoraoses on their DPs based on the analysis of molecular weight distribution of whole anionic cyclosophoraoses isolated from the $R$. meliloti 2011. Further application for inclusion complexation with these anionic cyclosophoraoses is now under investi- gation.

Acknowledgment. This work was supported by grants of Bioproducts and Biotechnology Research Group (01-J-BP01-B-59) from Ministry of Science and Technology in South Korea. SDG.

\section{References}

1. Palleschi, A.; Crescenzi, V, Gazz. Chim. HaI, 1985. 115, 243.

2. Choi, Y.: Yang, C.; Kim, H.: Jung, S. Carbohydr: Res. 2000, 326. 227 .

3. Koizumi, K.; Okada, Y.; lkeda, M. J. Incl Phenom 1984, 2, 891.

4. Lee, S.; Seo. D; Kim. H.; Jung. S. Carbolıdr: Res. 2001, 334 , 119.

5. Lee, S.; Kwon. C; Choi, Y; Seo. D; Kim, H.; Jung, S. I. Minobiol Biotechnol 2001, $11,463$.

6. Choi, Y.; Yang, C.: Kim, H.: Choe, T.; Jung, S. Bull Korean Chem. Soc. 2000, 21, 361.

7. Breedveld. M. W; Miller. K. J. Microbiolog1 1995, 141. 583.

8. Miller. K. J.; Kennedy. E. P.; Reinhold. V. N. Science 1986. 231 , 48.

9. Spaink, H. P. Plant Mol. Biol. 1992, 6, 997.

10. Batley, M.; Redmond, J. W.; Djordjevic, S. P.: Role, B. G. Biochim. Bioply's. Acta 1987, 961, 119.

11. Miller, K. J.; Gore, R. S.; Benesi, A. J, I. Bacteriol. 1988. 170. 4569 .

12. Hisamatsu. T.; Yamada. T.; Higashiura. T.; Ikeda. M. Carbohtud Res. 1987, 163, 115.

13. Miller, K. J.; Reinhold, V. N.; Weissborn, A. C.; kenedy, E. P. Biochim. Bioply's. Acta 1987, g1/1, 112.

14. Geiger, O.; Weissboun, A. C.; Kennedy. E. P. J. Bacteriol. 1991. 173,3021 .

15. Breedveld, M. W; Benesi. A. J.; Marco. A. L.; Miller, K. J. Appl. Emiron. Microbiol. 1995. 61, 1045.

16. Breedveld, M. W.: Dijkema, C.: Zevenhuizen, L. P. T. M. J. Gen. Microbiol 1993, 139, 3157.

17. Zevenhuizen, L. P. T. Z.; Velehuizen, A. van; Fokkens, R. H. Antonie Leetivenhoek 1990, 57, 173.

18. Read. S. M.; Currie. G.; Bacic, A. Carbohyd: Res. 1996. 281, 187.

19. Chen, F.-T. A.: Shen, G.: Evangelista, R. A. J. Chromatogr: A 2001, 924, 523.

20. Breedveld, M. W.; Zenvenhuizen, L. P. T. M.; Zehnder, A. J. B Appl. Emiron. Microbiol. 1990, 56, 2080.

21. Breedveld, M. W.; Yoo, J. S.; Reinhold, V. N.; Miller. K. J. J. Bacteriol. 1994, 176, 1047.

22. Kwon, C.; Choi, Y.; Kim, N.: Yoo, J.: Yang, C.: Kim, H.: Jung, S. J. Ind Phenom 2000, 36, 55. 